\title{
Uma história da imprensa (e do jornalismo): por entre os caminhos da pesquisa ${ }^{1}$
}

\author{
A history of the press (and journalism): wondering through research paths \\ Una historia de la prensa (y del periodismo): por entre los caminos de la investigación
}

DOI: $10.1590 / 1809-5844201821$

\author{
Marialva Barbosa ${ }^{1}$ \\ http://orcid.org/0000-0001-8875-7128
}

${ }_{1}^{1}$ (Universidade Federal do Rio de Janeiro, Escola de Comunicação, Programa de Pós-Graduação em Comunicação e Cultura. Rio de Janeiro - RJ, Brasil)

\section{Resumo}

O artigo faz uma reflexão metodológica sobre a pesquisa histórica na área da Comunicação, evidenciando não apenas o crescimento da perspectiva historiográfica, mas sobretudo a inclusão de novas abordagens. Para isso, analisa teses e dissertações produzidas na área da Comunicação de 1990 a 2016 que têm a história da imprensa/do jornalismo como temática central. Observa-se a mudança de paradigma dessas análises na última década, com a adoção de um olhar denso e plural e a percepção da história como trânsito entre tempos, fundamental para a compreensão dos processos comunicacionais. Objetiva-se apresentar, também, alguns cenários metodológicos que podem ser adotados em estudos cujo centro reflexivo é a questão histórica.

Palavras-chave: História do jornalismo. História da imprensa. Metodologia. Comunicação. História.

\begin{abstract}
This paper is a methodological reflection about historical research applied to the Communication field. It does not only focus on the historiographical perspective that has grown in the Communication field, but mainly on the inclusion of new approaches. For that purpose, this paper presents an analysis of doctoral thesis and master's dissertations produced in the Communication field from 1990 to 2016 that have the history of the press/journalism as a central theme. The results indicate a shift of the paradigm in these analyses through the last decade. We notice a plural and dense approach and a different perspective towards history, as a flow between times, which is essential for a better understanding of the communicational processes. This paper also aims at presenting some methodological scenarios, which can be applied to studies that have the historical issue as its reflexive core.
\end{abstract}

Keyworks: History of journalism. History of the press. Methodology. Communication. History.

1 Este artigo, com modificações e acréscimos, foi apresentado inicialmente no XV Congreso de la Asociación de Historiadores de la Comunicación, em 15 de setembro de 2017, na Universidade do Porto, Portugal. 


\section{Resumen}

El artículo hace una reflexión metodológica sobre la investigación histórica en el área de la Comunicación, evidenciando no sólo el crecimiento de la perspectiva historiográfica, sino sobre todo la inclusión de nuevos enfoques. Para esto, este artículo analiza más detenidamente tesis y disertaciones producidas en el área de la Comunicación, de 1990 a 2016, que tiene la historia de la prensa/del periodismo como temática central. Se observa un cambio de paradigma de esos análisis en la última década, con la adopción de una mirada densa y plural y la percepción de la historia como tránsito entre tiempos, fundamental para la comprensión de los procesos comunicacionales. Se pretende presentar, también, algunos escenarios metodológicos que pueden ser adoptados en estudios que tienen la cuestión histórica como centro reflexivo.

Palabras clave: Historia del periodismo. Historia de la prensa. Metodología. Comunicación. Historia.

\section{Introdução}

O olhar histórico sobre os processos e as práticas comunicacionais obriga inicialmente a uma reflexão acerca da forma como devemos considerar, em cada temporalidade particular, os meios de comunicação e de que maneira aquela sociedade se relacionava com a expressão pública comunicacional.

Em segundo lugar, pensando que a opção metodológica diz respeito não apenas a como entendemos o conhecimento científico, mas de que lugar histórico estamos falando, precisa-se, antes da escolha dos procedimentos de pesquisa - a metodologia como ação metódica -, definir a concepção de história de onde partimos.

Posteriormente, há que se especificar o contexto da análise, já que a pesquisa histórica exige a contextualização, sem a qual não estabelecemos referências nem presunções interpretativas no que se refere ao mundo que está sendo analisado.

Construir a história dos meios de comunicação é levar em conta primeiramente o que poderíamos definir como cena midiática existente em dado momento e lugar. Que mecanismos eram utilizados para que a fala comunicacional se multiplicasse nos espaços públicos? Como se dava a articulação entre produtores e receptores de textualidades? Como o público se relacionava com os meios mediante a imersão em tecnologias reprodutoras e multiplicadoras de mensagens? Qual era o caminho de efetivação dos processos da imprensa e como eles se configuravam como contexto midiático?

A tentativa de acessar o passado, entretanto, faz-se pela interpretação e análise dos documentos, compreendidos aqui na sua acepção mais ampla, que chegam até o presente sob o aspecto de vestígios. Essa interpretação eivada da subjetividade do pesquisador tem a marca da época em que foi produzida e está permanentemente sujeita a novas interpretações, revisões, reformulações. É com base nessa suspensão constante e nesse aspecto provisório que o conhecimento científico pode avançar.

Outra questão importante concerne à intencionalidade do documento. Nenhuma produção documental é neutra e sua durabilidade também indica certa propensão a já ter 
sido produzida visando a uma possibilidade futura. Quando se considera a própria produção midiática como documento de uma época, é preciso perceber igualmente que ela tinha uma relação especial com o seu presente histórico.

Ao falarem de si mesmos e, assim, se constituírem em fontes para sua própria história, os meios de comunicação, por outro lado, produzem uma fala memorável em que o passado é apresentado como portador de significâncias que dizem respeito muito mais a um ideal presumido do que deve ser fixado no futuro. Mas é dessas entranhas que devemos extrair significados sobre aquele mundo.

\section{Comunicação e história: confluências}

A Comunicação como lugar teórico de reflexão sobre os processos e as práticas comunicacionais privilegia as pesquisas que dizem respeito ao presente absoluto em que vivemos. Há preferência pela reflexão acerca dos processos que ainda estão em curso e mesmo atenção desmedida a temas que são emblematicamente construídos em torno de materiais empíricos que ocupam lugar privilegiado no cotidiano das práticas contemporâneas de comunicação. Assim, quando o Orkut era o último grito tecnológico no que se referia às redes sociais, essa temática foi exaustivamente discutida (mas nem sempre teoricamente refletida) por inúmeras pesquisas. Quando o Twitter ameaçou se tornar febre dos mecanismos de transmissão de mensagens, passou quase que naturalmente a ocupar o cenário dos objetos empíricos privilegiados nas pesquisas de comunicação. Agora assistimos à emergência dos memes.

Qual é a razão dessa preferência por processos ultracontemporâneos, por objetos empíricos que às vezes se esfacelam no decorrer das análises voltadas para um presentismo exacerbado?

Se por um lado podemos oferecer uma tentativa de interpretação com base na própria definição do que é a temática de análise da Comunicação - não necessariamente os meios e a produção midiática, mas as vinculações que se criam cotidianamente no mundo da vida nos processos contemporâneos mediados pela comunicação (o bios midiático, tal como definido por Sodré ${ }^{2}$, fazendo com que a explicação e a interpretação mais completa sobre os processos em curso sejam obrigatoriamente uma reflexão em torno do comunicacional -; por outro, há que considerar a forma como se vive a temporalidade, imersos que estamos num movimento da experiência contemporânea em que a articulação entre passado, presente e futuro parece ter sido esfacelada.

No atual regime de historicidade, como enfatiza Hartog (2013), a produção do tempo histórico figura-se suspensa. Isso faz com que a experiência contemporânea seja marcada por um presente perpétuo, “inacessível e quase imóvel que busca, apesar de tudo, produzir

2 Sobre o tema, ver: Sodré (2002, 2014). 
para si mesmo o seu próprio tempo histórico” (HARTOG, 2013, p.39). É como se não houvesse nada mais do que o presente. E são exatamente esse momento e a correspondente experiência contemporânea do tempo que o historiador designa como "presentismo".

Assim, os estudos que possuem dimensão histórica são inexpressivos diante da produção contemporânea presente nos programas de pós-graduação existentes hoje no Brasil (45 mestrados e 23 doutorados) ${ }^{3}$. Percorrendo as teses e dissertações, constata-se que, embora tenha havido mudanças no que diz respeito à concepção de história adotada, com considerável avanço em relação ao diagnóstico que produzimos há quase uma década (BARBOSA, 2010b) sobre os estudos históricos de Comunicação, no qual verificamos a supremacia de uma visão utilitária de história, com a perspectiva na maioria das vezes de iluminar processos observados no presente, ainda há muitos trabalhos que levam em conta as características discursivas dos veículos sem abordar a historicidade propriamente da imprensa/do jornalismo. Também sobressai uma visão particularista dos temas e problemas, privilegiando-se um periódico, um processo ou um período específico. Poucos são os estudos de síntese e ainda são muitos os que adotam uma concepção de história baseada na linearidade dos processos.

Após uma análise exaustiva das teses e dissertações tendo como temática a história da imprensa ou história do jornalismo ${ }^{4}$, chegamos ao escopo total de 47 teses e dissertações, que foram localizadas por meio da entrada "história do jornalismo" e 170 pela escolha da referência "história da imprensa”, perfazendo 217 pesquisas realizadas desde os anos 1990 até 2016, em todas as áreas de conhecimento.

Se quantificarmos as investigações por área, notamos que há a supremacia dos estudos realizados nos programas de pós-graduação em Comunicação, seguidos dos programas de pós-graduação em História ${ }^{5}$. Aparecem também pesquisas realizadas em Letras/Linguística, Educação e em áreas interdisciplinares, conforme Gráfico 1. Na categoria “Outros”, computamos um trabalho em cada uma das áreas mencionadas: Direito, Música, Ciência da Informação, Relações Internacionais, Filologia, Educação Física e Arquitetura.

3 Os números apresentados no Documento de Área da Coordenação de Aperfeiçoamento de Pessoal de Nível Superior (Capes) referem-se aos programas criados até 2015. Ver: Brasil (2016).

4 Para chegar a esse número, além das entradas no Banco de Teses e Dissertações da Capes pela temática história da imprensa ou do jornalismo, fizemos também uma análise baseada no nome dos pesquisadores/orientadores mais citados na área. Para o artigo, foram examinadas mais detidamente as 91 teses e dissertações desenvolvidas na área da Comunicação.

5 Para uma análise das teses e dissertações de história da imprensa/do jornalismo produzidas na área de História, ver: Barbosa (2017). 
Gráfico 1 - Teses e dissertações de história da imprensa/do jornalismo divididas por área de conhecimento

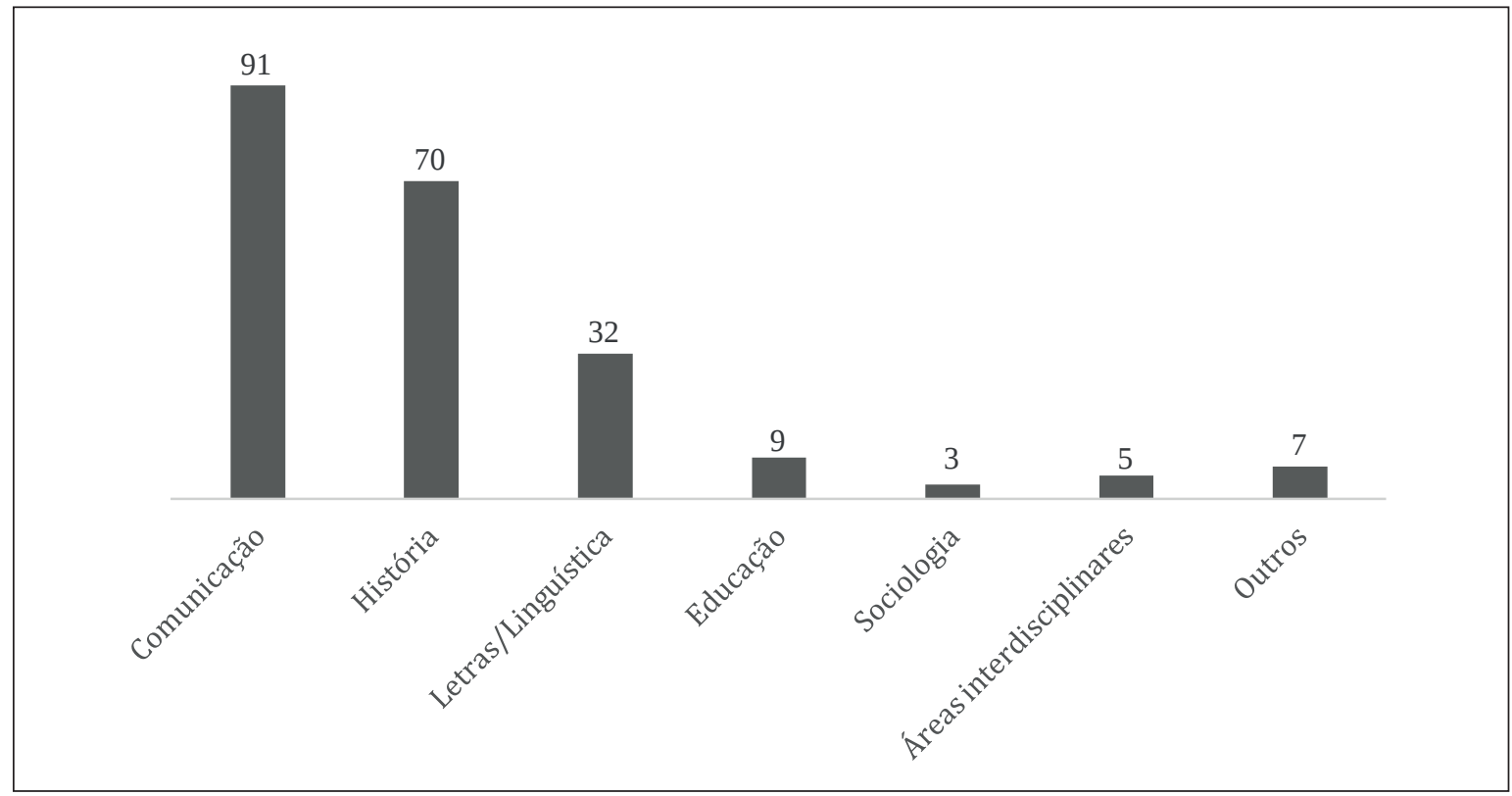

Fonte: Banco de Teses e Dissertações da Coordenação de Aperfeiçoamento de Pessoal de Nível Superior (Capes).

\section{Comunicação e olhar histórico}

Como já enfatizamos, apesar da pouca aderência do passado como possibilidade reflexiva para a área da Comunicação, observa-se, nos últimos anos, que as pesquisas históricas concernentes à imprensa passaram a ser dominantes na Comunicação, se comparadas com as que foram desenvolvidas em outras áreas de conhecimento (Gráfico 1).

Essa constatação sugere que a Comunicação pode oferecer os referenciais teóricos e metodológicos para lidar com o conhecimento histórico sobre a imprensa de maneira particular e os processos midiáticos em termos gerais. É possível mesmo aferir que, ao realizar seus estudos presentistas ao longo de mais de 50 anos, estaria a Comunicação também produzindo uma história do tempo passado (BARBOSA, 2016).

Mas quais são as características desses trabalhos? Que concepção de história tem prevalência? As limitações identificadas por Ribeiro (2008) ainda figuram nessas análises ${ }^{6}$ ? Quais são os avanços teóricos e metodológicos encontrados nas pesquisas?

Analisando as 91 teses e dissertações produzidas na área da Comunicação de 1990 a 2016, notamos que ao longo desses 26 anos houve aumento substancial das que adotaram

6 Ribeiro (2008) identifica entre os principais impasses teóricos e metodológicos das pesquisas sobre história da Comunicação e da mídia no Brasil os seguintes: predomínio de estudos regionais e locais; ausência de pesquisa comparativa; poucos trabalhos de síntese; Sudeste como espelho do país; memorialismo; centralidade na ação individual; privilégio na ruptura e temporalidade linear; caráter descritivo; predomínio da história política; desconsideração do âmbito externo; desconsideração da dimensão interna. 
uma premissa de natureza histórica nos estudos de Comunicação, bem como a pulverização das produções por diversas instituições de ensino, refletindo a ampliação dos programas de pós-graduação, percebida sobretudo a partir dos anos 2000 e com mais intensidade na primeira década do século XXI (Gráfico 2).

Gráfico 2 - Teses e dissertações em Comunicação sobre história da imprensa/do jornalismo nas universidades brasileiras ${ }^{7}$

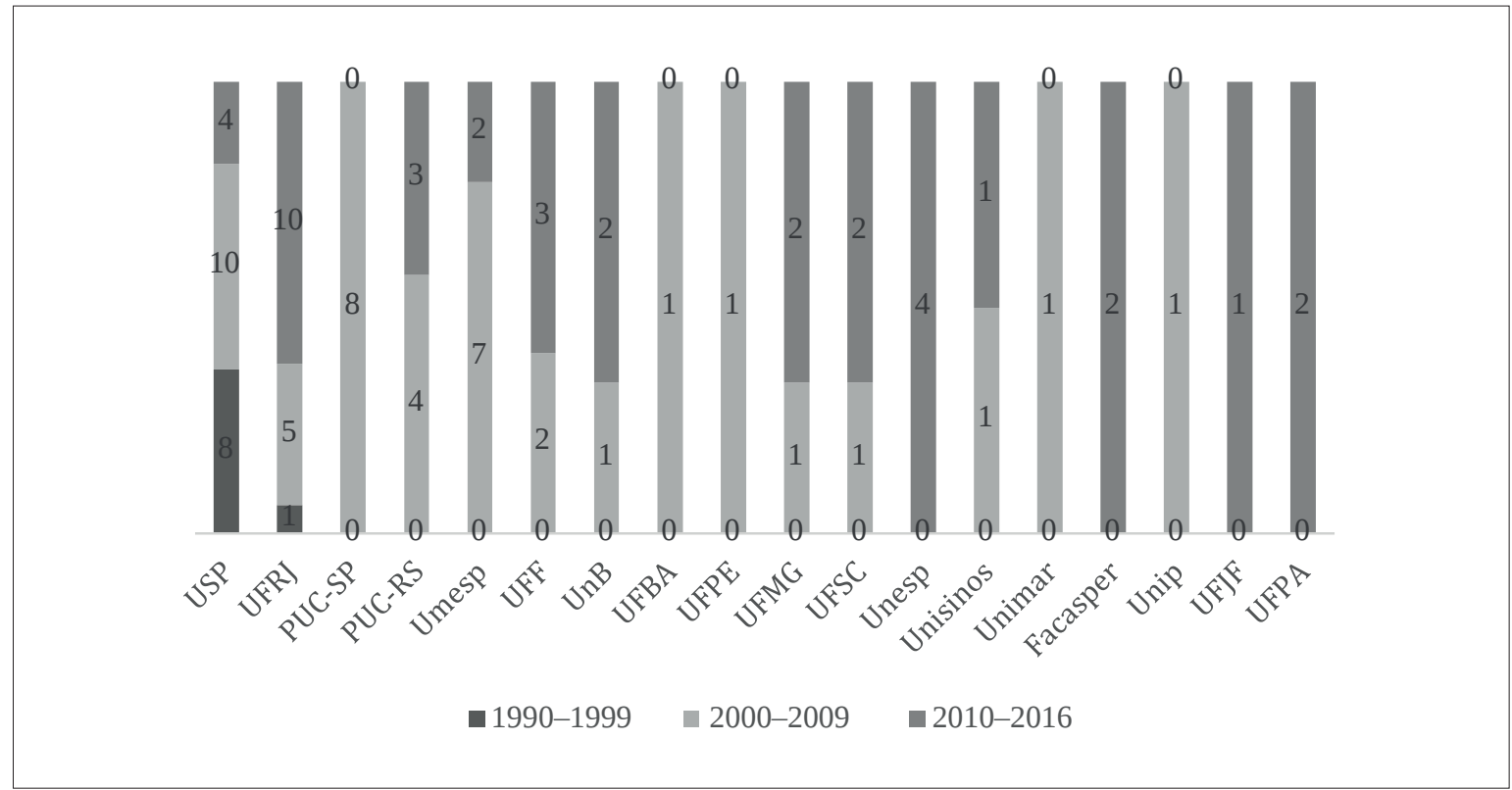

Fonte: Banco de Teses e Dissertações da Capes.

Nos nove trabalhos da década de 1990 havia o predomínio da concepção de história como ação personalista de alguns nomes elevados a ícones do jornalismo, ao lado de pesquisas de caráter descritivo, que faziam da análise dos textos meio para a compreensão de um aspecto que nada tinha a ver com a história da imprensa, como, por exemplo, a análise do discurso midiático sobre o desenvolvimento e os significados da democracia. Viu-se também a prevalência de pesquisas que enfocavam apenas um periódico.

Já os 44 trabalhos da década seguinte, conforme o Gráfico 3, indicam considerável avanço: ampliação das análises em direção às sínteses históricas e aumento das pesquisas de regiões até então não consideradas (Maranhão, Amazonas, Roraima, Santa Catarina,

7 USP: Universidade de São Paulo; UFRJ: Universidade Federal do Rio de Janeiro; PUC-SP: Pontifícia Universidade Católica de São Paulo; PUC-RS: Pontifícia Universidade Católica do Rio Grande do Sul; Umesp: Universidade Metodista de São Paulo; UFF: Universidade Federal Fluminense; UnB: Universidade de Brasília; UFBA: Universidade Federal da Bahia; UFPE: Universidade Federal de Pernambuco; UFMG: Universidade Federal de Minas Gerais; UFSC: Universidade Federal de Santa Catarina; Unesp: Universidade Estadual Paulista “Júlio de Mesquita Filho”; Unisinos: Universidade do Vale do Rio dos Sinos; Unimar: Universidade de Marília; Facasper: Faculdade Cásper Líbero; Unip: Universidade Paulista; UFJF: Universidade Federal de Juiz de Fora; UFPA: Universidade Federal do Pará. 
Paraná) e de investigações que enfocam, de fato, processos jornalísticos (11), constituindo trabalhos verdadeiramente sobre história dos meios.

Gráfico 3 - Abordagem dos trabalhos de 2000 a $2009^{8}$

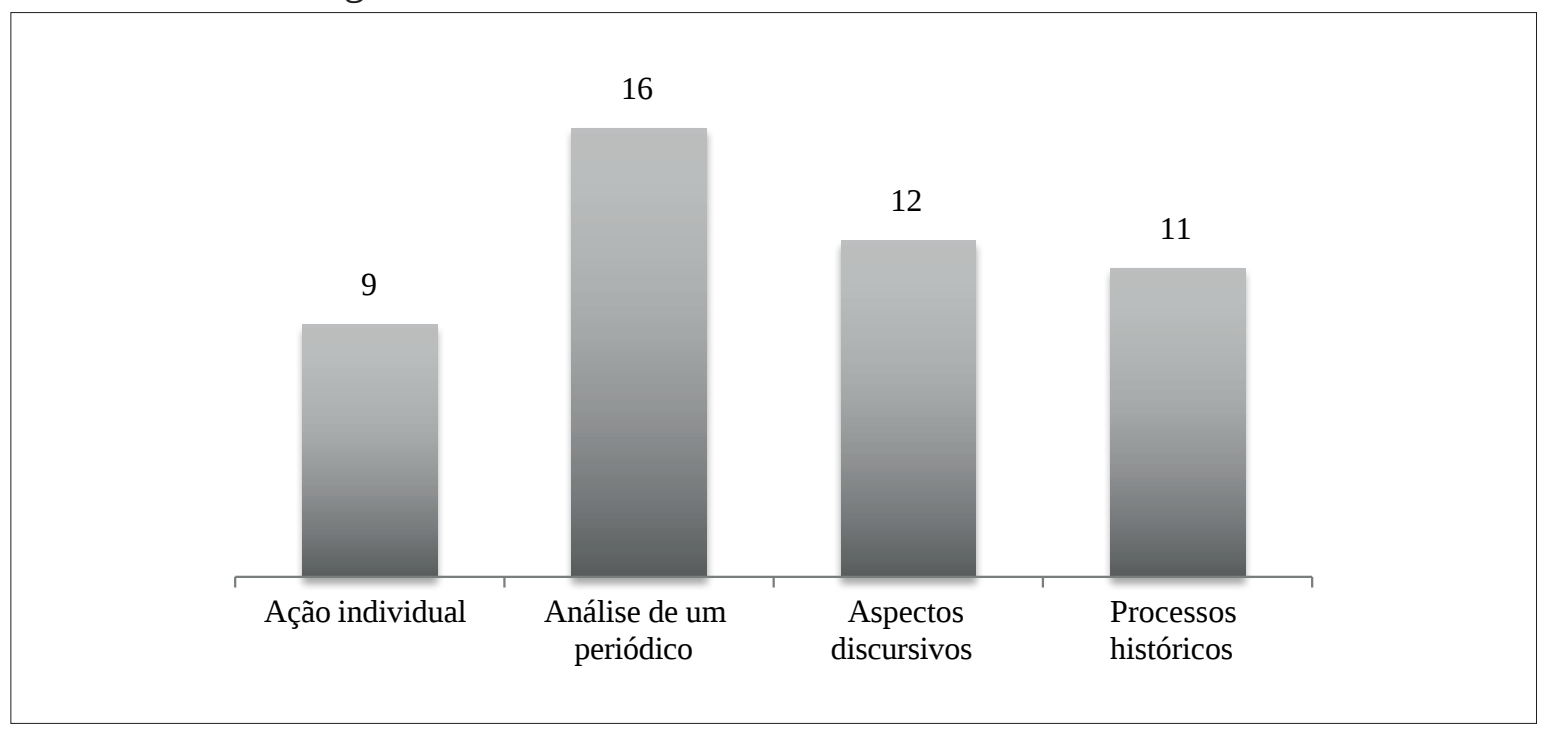

Fonte: Banco de Teses e Dissertações da Capes.

Apesar disso, veem-se ainda trabalhos tributários da ideia de história baseada em grandes feitos ou particularizando a atuação de personagens numa perspectiva memorialística. Percebe-se também a grande quantidade de pesquisas (16) que se dedicam a analisar um ou no máximo dois periódicos. Logo, prevalece a concepção de que ao se referir aos discursos de jornais ou revistas do passado se estaria produzindo automaticamente estudos de natureza histórica.

Na década 2000 - 2009, seis trabalhos podem ser considerados de síntese histórica (RIBEIRO, 2000; FRANCISCATO, 2003; GENTILLI, 2003; MENDES, 2007; COSTA, 2007; MESSAGI JR., 2009). Todos oferecem expressiva contribuição à pesquisa, pela abordagem conceitual complexa, pela proposta de novas opções teóricas e metodológicas e pela adoção de uma perspectiva inovadora em relação à análise de alguns processos sobre a imprensa brasileira (a questão da modernização dos jornais, por exemplo). Há ainda a emergência de pesquisas sobre a construção da identidade do jornalista brasileiro (SILVA, 2007; LOPES, 2007), que propõem a interpretação do profissionalismo fundamentada em parâmetros de natureza histórica.

No tocante às pesquisas da década seguinte (2010 - 2016), conforme o Gráfico 4, foram produzidas 34 teses e dissertações tendo como centro reflexivo a história da

8 Nota: a soma aqui chega a 48 trabalhos, já que alguns foram classificados em mais de uma categoria. 
imprensa/do jornalismo. Há a ampliação da área geográfica das pesquisas, com a inclusão de reflexões acerca de processos jornalísticos das regiões Norte, Nordeste e Sul. A imprensa do interior também foi contemplada em algumas pesquisas (interior da Bahia e de São Paulo, por exemplo).

Observa-se franco declínio da perspectiva histórica como efeméride e baseada na ação de atores individuais. Nota-se a emergência de novas perspectivas ao considerar os indivíduos como emblemas de um período histórico, no qual o particularismo das ações dessas personagens é levado em conta para a reflexão e análise de cenários comunicacionais mais amplos sob um novo olhar teórico e metodológico (SANTOS, 2016; BERTOL, 2016).

Gráfico 4 - Abordagem dos trabalhos de 2010 a $2016^{9}$

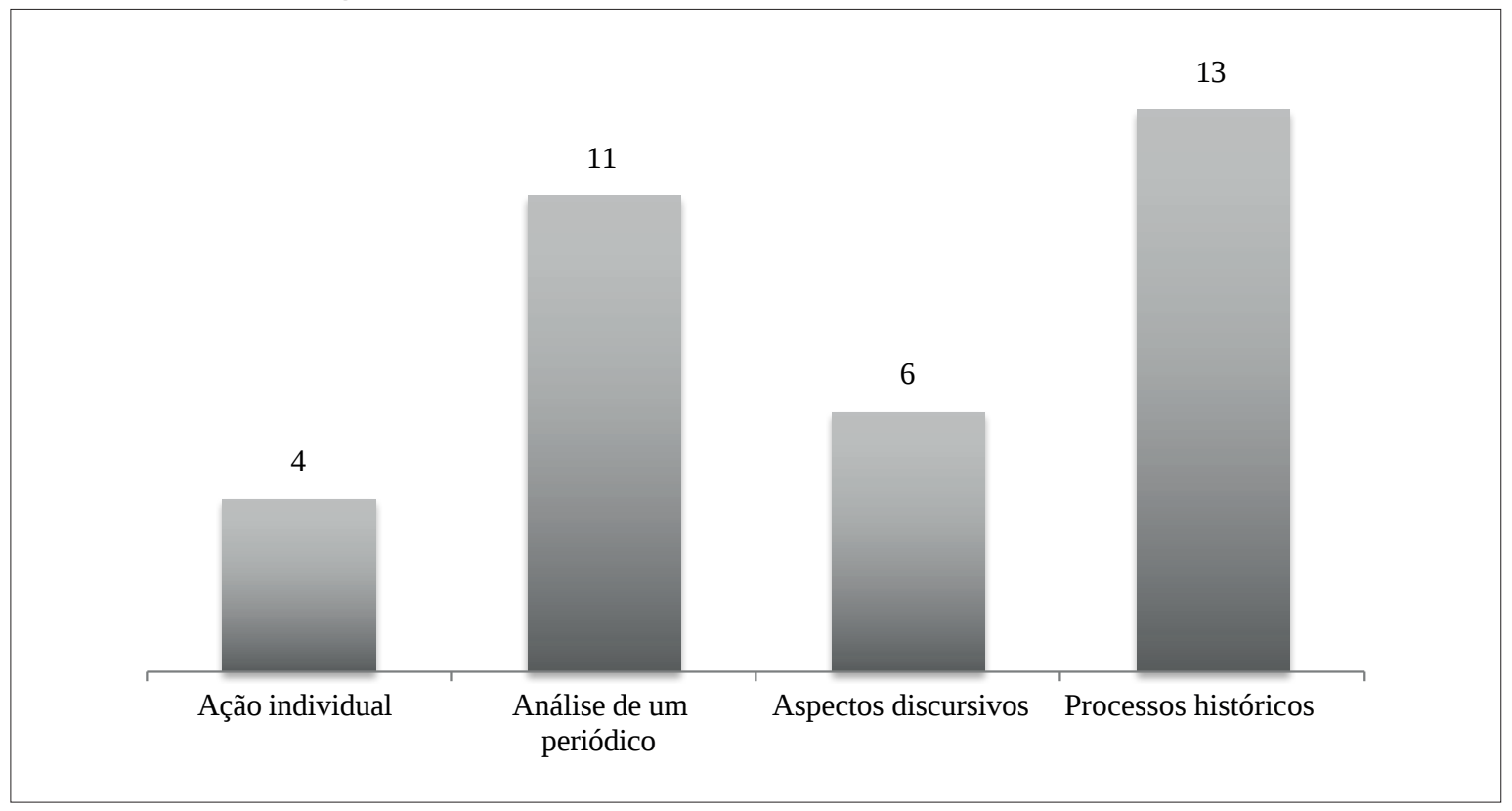

Fonte: Banco de Teses e Dissertações da Capes.

No período 2010 - 2016, há um considerável declínio da percepção de que ao se referir a discursos produzidos no passado se estariam construindo estudos históricos. Ainda que exista o domínio de pesquisas que enfocam um periódico (o que também pode ser explicado pela maior quantidade de dissertações de mestrado), vê-se a expansão de estudos inovadores em termos teóricos e metodológicos (MATHEUS, 2010; CASTILHO, 2010; LOPES, 2012; MELO, 2014; REIMBERG, 2015; SANTOS, 2016; BERTOL, 2016; JÁCOME, 201710; MOREIRA, 2015).

9 Nota: foi considerada a totalidade dos 34 trabalhos, optando-se por categorizar a opção dominante.

10 Embora a tese de Jácome, pela UFMG, tenha sido defendida no início de 2017, consideramos como uma produção realizada em 2016 , para fins de computação geral da produção do período. 


\section{Cenários metodológicos}

A análise da imprensa numa perspectiva histórica pode adotar como cenário metodológico a percepção de um sistema de comunicação complexo, no qual as dimensões interna e externa dos fenômenos devem ser consideradas. Os periódicos fazem parte de um sistema de comunicação com temporalidades e territorialidades próprias. Assim, os processos jornalísticos e as práticas dos atores sociais (os jornalistas, o público etc.) devem ser buscados e interpretados à luz de problemáticas específicas.

Utilizando esses pressupostos, produzimos algumas obras de síntese histórica para compreender os processos midiáticos dos séculos XIX e XX no Brasil (BARBOSA, 2007; 2010a; 2013), incluindo na abordagem outras dimensões importantes: a concepção de que as textualidades produzidas - mesmo as ficcionais - se referem a um mundo ideal e simbolicamente existente, mas que deixam brechas para perceber cenários do mundo como representação (consideração fundamental para o uso da literatura como fonte histórica); o uso dos próprios jornais como fonte para a sua história com base nos vestígios de suas tessituras narrativas, levando em conta as estratégias de autorreferenciação (RIBEIRO, 2006) e os trabalhos de memória produzidos em relação ao passado e com presunção de futuro; e a substituição da linearidade dos períodos pela axialidade (RICOEUR, 1997) dos problemas de pesquisa, notando as rupturas e as continuidades históricas.

Se esses são alguns pressupostos metodológicos essenciais, nos últimos anos têm surgido pesquisas indicando outros caminhos. Para este artigo, vamos analisar brevemente as possibilidades metodológicas oferecidas por seis teses de doutorado defendidas entre 2010 e 2016 tendo como referência a história da imprensa/do jornalismo. São elas: Matheus (2010), Lopes (2012), Moreira (2015), Reimberg (2015), Santos (2016) e Jácome (2017).

As razões dessa escolha dizem respeito às perspectivas metodológicas adotadas: cinco foram consideradas obras de síntese, por tratarem de processos mais holísticos envolvendo a história da imprensa (MATHEUS, 2010; LOPES, 2012; MOREIRA, 2015; REIMBERG, 2015; JÁCOME, 2017), e uma por promover uma ruptura metodológica nas análises que enfocam personagens significativas, apresentando o biografismo sob um novo olhar (SANTOS, 2016).

Contemplando de maneira macro os trabalhos, observamos que eles se enquadram em mais de uma categoria: três referem-se a uma história dos jornalistas e não à do jornalismo (LOPES, 2012; REIMBERG, 2015; SANTOS, 2016); três abordam processos históricos da imprensa de modo mais abrangente (MOREIRA, 2015; LOPES, 2012; JÁCOME, 2017); outras três enfatizam também a construção de modernidades no jornalismo brasileiro (MATHEUS, 2010; SANTOS, 2016; JÁCOME, 2017); e uma procura interpretar o que denomina de mudanças estruturais na organização político-midiática ao longo do século XX (MOREIRA, 2015). 
O ponto nevrálgico dos processos de modernização da imprensa brasileira, seja em referência ao início do século XX, seja ao momento emblema, a década de $1950^{11}$, é objeto referencial da tese de Santos (2016) e central de duas outras (MATHEUS, 2010; JÁCOME, 2017). Tais investigações tomam como ponto de partida as lógicas das temporalidades como ação humana na duração, para fornecer novas explicações para os processos de transformação da imprensa em dois momentos. Com uma tese densa, Jácome (2017) constrói sua argumentação em torno da modernização da imprensa nos anos 1950, procurando mostrar se, de fato, houve uma modernização (e que ideia de moderno estava contida no argumento) e como as ações do próprio jornalismo sedimentaram esse discurso. Enfrenta, assim, um cânone das explicações históricas em torno dos processos da imprensa no Brasil, fazendo avançar o conhecimento ao oferecer uma nova interpretação.

Outra consideração mais genérica que se pode fazer em relação a esses trabalhos é a forma como os autores transitam pelas temporalidades. Em todos os casos, o passado não serve apenas para iluminar o presente e nem existe em essência. As pesquisas transitam do passado para o presente e do presente novamente para o passado estabelecendo um fluxo de continuidades - que pressupõe rupturas também fundamentais -, numa história peculiar em que o contemporâneo figura explicitamente em cena. Não há a demarcação do tempo, ou, quando ele aparece, é definido como o tempo das durações: o século e os hiatos de modernidade (MATHEUS, 2010), a experiência longeva dos jornalistas no mundo do trabalho (REIMBERG, 2015), a trajetória histórica na construção de uma identidade profissional específica (LOPES, 2012), ou o longo tempo de constituição estrutural dos impérios midiáticos brasileiros (MOREIRA, 2015). Mesmo aquelas pesquisas que se concentram mais claramente num período, os anos 1950 (JÁCOME, 2017), ou acompanhando as “travessias comunicacionais” de um tipógrafo esquecido do interior da Bahia (SANTOS, 2016), institui-se o trânsito entre os tempos idos e a contemporaneidade que se reflete na construção de retóricas de modernidade em torno de figuras que não foram emblemáticas, mas que podem se tornar personagens-síntese de um movimento mais amplo.

No tocante aos caminhos metodológicos, há várias proposições instigantes. A pesquisa de Moreira (2015) é a menos inovadora em termos de proposta teórica e metodológica e possui também a limitação de se valer, sobretudo, de estudos históricos já realizados. Embora especifique que adotará uma visão de história que considera a subjetividade do pesquisador, não havendo, portanto, recuperação verdadeira do passado, e que lançar mão da história como método é lidar “com atos humanos singulares, inseridos num dado contexto e marcados por uma temporalidade específica” (MOREIRA, 2015, p.20), a rigor, o trabalho é tributário de uma visão de história que pretende recuperar a trajetória da imprensa do

11 A década de 1950 é considerada nos estudos sobre história do jornalismo como o momento inflexivo da chamada modernização da imprensa no Brasil, tornando-se uma espécie de momento emblema de um processo que, a rigor, começou no início do século XX. Sobre o tema, ver Ribeiro (2000). 
passado até o presente. O uso escasso de fontes inéditas e a prevalência de releituras sobre diversos autores, aceitando em totalidade as suas teses, também enfraquece o trabalho do ponto de vista teórico e metodológico.

Valendo-se da construção de “tipos ideais”, tal como foram concebidos por Weber (1999), para a caracterização dos processos midiáticos ao longo do século XX, o autor remarca que há uma ruptura nos “paradigmas do jornalismo” da opinião em direção à informação, movimento fundamental, na sua tese, para a constituição dos conglomerados midiáticos, a partir dos anos 1920 (MOREIRA, 2015). Entretanto, há que se considerar que Moreira (2015) avança na proposição de um modelo de análise da mídia mediante reduções conceituais capazes de construir parâmetros para a caracterização da imprensa ao longo do século XX, partindo do pressuposto de que há momentos de predomínio de certas práticas e processos jornalísticos.

As três teses que tomam o jornalista e não o jornalismo como historicidade oferecem percursos metodológicos importantes. A tese de Reimberg (2015) emprega a entrevista como ferramental de parte de sua pesquisa, procurando encontrar nas memórias e vivências dos jornalistas (21 profissionais de 25 a 82 anos) as relações de prazer e de sofrimento que estes estabelecem com a prática profissional. A investigação inclui também o que a autora denomina de contexto histórico, produzindo uma lista de questões relativas à organização do trabalho e da saúde do trabalhador com a história das práticas organizacionais do jornalismo.

Mas a inovação do trabalho é o trânsito que oferece quanto aos processos de produção e às relações de trabalho no jornalismo entre várias décadas. Mostrando as inflexões dos anos 1980, 1990, 2000 e do momento de produção da tese (2015), utiliza vários pressupostos da historiografia ao propor uma interpretação dos sentidos e afetos que envolvem o trabalho do jornalista usando como instrumento as entrevistas. Incluindose subjetivamente na pesquisa - ela própria é jornalista -, a autora referenda a produção de suas entrevistas nos pressupostos teóricos da memória (REIMBERG, 2015), sobretudo na perspectiva do lugar posicionado de onde falam os jornalistas e os enquadramentos de memória (POLLAK, 1989).

Para a realização das entrevistas, Reimberg (2015) procura associar esses momentos de ouvir o outro à dinâmica da história, ou seja, contextualizando os vários tempos e considerando a historicidade dos grupos estudados e dos processos envolvidos, além dos espaços de análise como lugares de consenso e de conflitos, de subordinação e resistência. Assim, os atores jornalistas que aparecem como produtores de uma práxis memorável são também autores e fruto de seu tempo histórico (REIMBERG, 2015, p.35-36). Na sua práxis interpretativa, a autora percebe o discurso do outro como um saber partilhado e marcado pela tradição, pela cultura e pelas conjunturas. Não há verdade essencialista nos sentidos que são expressos nas articulações textuais e memoráveis. 
A segunda tese que se ocupa dos processos históricos de construção do jornalismo como prática profissional e da formação das chamadas identidades jornalísticas foi desenvolvida por Lopes (2012). O trabalho, uma continuação bastante adensada das pesquisas que a autora vinha desenvolvendo desde o mestrado (LOPES, 2007), objetiva investigar a identidade do jornalista na contemporaneidade, o que obriga a refletir sobre questões que dizem respeito aos "fazeres, valores e poderes do jornalismo" (LOPES, 2012, p.20). Para isso, sugere a análise retórica das vozes inseridas nesses múltiplos debates, destacando o capital simbólico adquirido pelo grupo ao longo do tempo. A autora considera fundamental a adoção de um olhar histórico sobre a formação do jornalista, escolhendo propositadamente a dimensão cronológica do problema, mas elege alguns momentos como axiais na construção do cenário profissional do jornalismo: as décadas de 1950 e 1960; os anos da ditadura militar no Brasil; e de redemocratização do país (LOPES, 2012). Nesse processo, as transformações das práticas jornalísticas na contemporaneidade merecem uma análise pormenorizada, mostrando as instabilidades, os conflitos e as tensões da construção identitária.

No que tange às proposições históricas, Lopes (2012) propõe, de maneira inovadora, uma análise retórica para analisar vozes do passado (ou do presente tornado passado). Nesse sentido, a visão processual numa longa duração é fundamental para a percepção das identidades jornalísticas como produto da construção histórica.

Por último, em referência à opção metodológica como proposição prática, a tese de Lopes (2012), entre todas, é a que adota o maior número de procedimentos, desde a exaustiva análise documental até a realização de entrevistas, passando pela aplicação de questionários dirigidos e pela realização de observação não participante. Esse passeio em torno de vários materiais empíricos e a maneira como a autora trabalha as diversas tramas documentais constituem o ponto alto da pesquisa, elaborando um verdadeiro mapa disperso e, ao mesmo tempo, interconectado sobre uma multiplicidade documental (LOPES, 2012), fórmula adotada em profusão nas pesquisas realizadas na história, mas pouco utilizada na área de Comunicação.

Enfim, vamos nos referir às três teses que têm a chamada modernização do jornalismo brasileiro como ancoragem teórica para o desenvolvimento de múltiplos cenários metodológicos (MATHEUS, 2010; SANTOS, 2016; JÁCOME, 2017), as quais possuem abordagens diametralmente opostas. Enquanto Matheus (2010), ao estudar a semantização do tempo produzida pelo jornalismo, ampliando as reflexões de Franciscato (2003) na década anterior, se vale da questão narrativa para analisar a construção discursiva do jornalismo, sempre na perspectiva da relação entre passado, presente e futuro; Santos (2016) procura mostrar como a construção da modernidade do jornalismo na década de 1950 oferecia um trânsito temporal entre lugares culturais distintos (as capitais e o interior), o que orientava processos contrários, mas igualmente a busca por utopias para o jornalismo. Por sua vez, Jácome (2017) procura mostrar os cenários de modernidade que estavam sendo 
construídos e como isso se dava, além dos argumentos dos próprios homens de imprensa da década de 1950.

Do ponto de vista metodológico, Santos (2016) realiza um trabalho inovador, utilizando como ferramental metodológico os pressupostos da micro história, para, fundamentada na construção da trajetória de um tipógrafo jornalista desconhecido do interior da Bahia, examinar as contradições, os limites, as reconfigurações, os desejos e as utopias que são sedimentados e erigidos em torno das transformações do jornalismo brasileiro a partir da segunda metade do século XX. Com base no pressuposto de que a história é ação humana no tempo, sendo produto da interpretação do pesquisador, que, por vezes, produz uma bricolagem dos agoras para acessar o passado, a autora percebe o passado igualmente como ruído a ser interpretado. Assim, procura visualizar os circuitos de comunicação existentes no interior, haja vista as travessias comunicacionais de uma personagem, recuperando a trajetória de um homem comum, os trânsitos entre o mundo oral e o dos letrados, numa dinâmica complexa de interpretação de uma vida como história.

Já Matheus (2010), do ponto de vista metodológico, toma a temporalidade como demarcação axial da história, vê a narrativa como trânsito imprescindível da história e adota a perspectiva de que a visão de história escolhida deve ser concebida na relação com a especificidade do contexto que averigua - no seu caso, o contexto temporal das construções jornalísticas. Produz uma análise em que a ótica processual é básica, ainda que eleja na sua pesquisa empírica momentos axiais temporais, baseada nas significâncias construídas na história e pela história (mesmo com o aval narrativo do próprio jornalismo). Do ponto de vista empírico, desenvolve uma minuciosa análise das edições comemorativas de três jornais centenários (Jornal do Brasil, Jornal do Commercio e O Fluminense), além de interpretar o reordenamento de representações de alguns acontecimentos simbólicos do jornalismo.

O trabalho de Jácome (2017) é um exemplo acabado de como podemos e devemos interpretar processos históricos à luz de argumentações do mundo da comunicação. A pesquisa não é uma tese histórica sobre o jornalismo, mas muito mais: trata-se de uma reflexão revestida dos pressupostos da historiografia para pensar a construção de um diálogo de um presente forte (como o autor mesmo qualifica) com um passado que é também fruto de tradições diversas.

Para ele, a questão não consiste em polemizar com uma interpretação canônica do jornalismo brasileiro (a sua modernização), mas perceber que tipo de relação o jornalismo “estabelece com a realidade histórica” (ou realidades históricas, como ele sugere) (JÁCOME, 2017, p.47) e os seus modos de saber o mundo. O avanço da tese, tal como as anteriores, está em construir uma reflexão acerca do jornalismo/da imprensa sob o ponto de vista de um olhar comunicacional, utilizando, porém, os pressupostos historiográficos como ponto inflexivo. Assim, indispensável analisar o jornalismo como um fenômeno histórico-social complexo (JÁCOME, 2017), interpretando não o passado dos fenômenos jornalísticos, no entanto a historicidade dos seus processos. 
Ao construir a parte metódica da sua pesquisa, indo aos arquivos e aos documentos para descortinar os múltiplos jornalismos produzidos em um longo percurso do tempo, Jácome (2017) parte da premissa interpretativa e observa os documentos, o que foi guardado e é novamente referenciado como "uma experiência viva e comunicativa, da qual também somos parte” (JÁCOME, 2017, p.19). Assim, procura "seguir o discurso da modernização, buscando desestabilizar sua concepção linear e circular da história” (JÁCOME, 2017, p.19) a partir de novas perguntas.

\section{Considerações finais}

Resumidamente, neste breve diagnóstico, podemos aferir três aspectos importantes na construção do campo histórico nos estudos da Comunicação. Em primeiro lugar, observamos a predominância das interpretações históricas da imprensa/do jornalismo na Comunicação, revelando que os parâmetros teóricos e metodológicos elaborados na área passaram a ter prevalência. Esse movimento parece indicar o reconhecimento do lugar de fala da Comunicação como lócus privilegiado para refletir sobre processos históricos da mídia de maneira geral.

O segundo ponto está na emergência, sobretudo na última década, do que poderíamos denominar de olhar historiográfico na área da Comunicação, mesmo em pesquisas que não têm a intencionalidade de recuperar o passado. Essas investigações, movendo-se em múltiplas temporalidades, do presente até o passado e vice-versa, preocupam-se muito mais com processos históricos do que com uma história stricto sensu da imprensa/do jornalismo.

Chama também a atenção, em terceiro lugar, o deslocamento do olhar de uma história dos processos para uma história que coloca em proeminência os atores sociais, partilhando uma visão epistemológica de trânsito metodológico em direção ao mundo da vida. São as ações humanas, os sentidos, as experiências, os sentimentos, as emoções que produzem uma história repleta de significado.

Ao fim da leitura dessas teses, temos a sensação de que toda a cruzada que empreendemos (ao lado de diversos outros pesquisadores) para construir um campo historiográfico para uma história da imprensa/do jornalismo no Brasil não foi em vão. Achamo-nos diante de estudos que inovam teórica e metodologicamente, apresentando propostas e vieses de análise que configuram um campo historiográfico dos processos comunicacionais vistos em toda a sua complexidade.

\section{Referências}

BARBOSA, M. História cultural da imprensa: 1900-2000. Rio de Janeiro: Mauad X, 2007.

História cultural da imprensa: 1800-1900. Rio de Janeiro: Mauad X, 2010a.

História dos sistemas de comunicação: balanço de um percurso teórico. Conexão, Caxias do Sul, v.17, p.11-29, 2010b. 
História da comunicação no Brasil. Petrópolis: Vozes, 2013.

A pluralidade de modelos interpretativos nas Ciências Humanas e o lugar da Comunicação. In: MOURA, C. P.; LOPES, M. I. V. Pesquisa em comunicação: metodologias e práticas acadêmicas. Porto Alegre: EDIPUCRS, 2016.

Comunicação: uma história do tempo passando. Transversos, Rio de Janeiro, n.11, dez. 2017.

BERTOL, R. A crítica literária em circuitos jornalísticos: José Veríssimo na imprensa da belle époque carioca. 2016. 243 f. Tese (Doutorado em Comunicação) - Universidade Federal do Rio de Janeiro, Rio de Janeiro.

BRASIL. Ministério da Educação. Documento de área: Ciências Sociais Aplicadas 1. Ministério da Educação, 2016. Disponível em: <http://www.capes.gov.br/images/documentos/Documentos_de_area_2017/31_CSA_I_ docarea_2016.pdf>. Acesso em: 10 abr. 2018.

CASTILHO, M. Patrimônio dos próprios jornalistas: o Prêmio Esso, a identidade profissional e as relações entre imprensa e Estado (1964-1978). 2010. 340 f. Tese (Doutorado em Comunicação) - Universidade Federal do Rio de Janeiro, Rio de Janeiro.

COSTA, C. R. A revista no Brasil, o século XIX. 2007. 292 f. Tese (Doutorado em Comunicação) - Escola de Comunicação e Artes, Universidade de São Paulo, São Paulo.

FRANCISCATO, C. E. A atualidade do jornalismo: bases para uma delimitação teórica. 2003. 335 f. Tese (Doutorado em Comunicação) - Universidade Federal da Bahia, Salvador.

GENTILLI, V. I. Sistema midiático e a crise do jornalismo: dos anos 50 à decadência posterior a 80. 2003. 228 f. Tese (Doutorado em Comunicação) - Escola de Comunicação e Artes, Universidade de São Paulo, São Paulo.

HARTOG, F. Regimes de historicidade: presentismo e experiências do tempo. Belo Horizonte: Autêntica, 2013.

JÁCOME, P. O jornalismo como singular coletivo: reflexões sobre a historicidade de um fenômeno moderno. 2017. 259 f. Tese (Doutorado em Comunicação) - Universidade Federal de Minas Gerais, Belo Horizonte.

LOPES, F. L. Auto-referenciação e construção da identidade jornalística. 2007. 257 f. Dissertação (Mestrado em Comunicação) - Universidade Federal do Rio de Janeiro, Rio de Janeiro

Jornalista por canudo. O diploma e o curso superior na construção da identidade jornalística. 2012.

316 f. Tese (Doutorado em Comunicação) - Universidade Federal do Rio de Janeiro, Rio de Janeiro.

MATHEUS, L. C. Comunicação, tempo e história. Tecendo o cotidiano em fios jornalísticos. 2010. 268 f. Tese (Doutorado em Comunicação) - Universidade Federal Fluminense, Niterói.

MELO, A. Na ordem do tempo: a sistematização do passado no Jornal do Brasil (1962-1974). 2014. 213 f. Dissertação (Mestrado em Comunicação) - Universidade Federal do Rio de Janeiro, Rio de Janeiro.

MENDES, J. F. O silêncio das Gerais: o nascimento tardio e a lenta consolidação dos jornais mineiros. 2007. 212 f. Tese (Doutorado em Comunicação) - Universidade Metodista de São Paulo, São Paulo.

MESSAGI JR., M. O texto jornalístico no centro de uma revisão da história da imprensa no Brasil. 2009. 274 f. Tese (Doutorado em Comunicação) - Universidade do Vale do Rio dos Sinos, São Leopoldo.

MOREIRA, M. H. T. Do partidarismo à informação: as mudanças estruturais no jornalismo brasileiro e a formação dos impérios midiáticos. 2015. 213 f. Tese (Doutorado em Comunicação) - Universidade de Brasília, Brasília.

POLLAK, M. Memória, esquecimento, silêncio. Estudos Históricos, Rio de Janeiro, v. 2, n. 3, p. 3-15, 1989.

REIMBERG, C. O. O exercício da atividade jornalística na visão dos profissionais: sofrimento e prazer na perspectiva teórica da psicodinâmica do trabalho. 2015. 376 f. Tese (Doutorado em Comunicação) - Escola de Comunicação e Artes, Universidade de São Paulo, São Paulo. 
RIBEIRO, A. P. G. Imprensa e história no Rio de Janeiro dos anos 50. 2000. 194 f. Tese (Doutorado em Comunicação) - Universidade Federal do Rio de Janeiro.

Velhos jornalistas: memória, velhice e identidade profissional. In: FREIRE FILHO, J.; VAZ, P. (Orgs.).

Construções do tempo e do outro: representações e discurso midiático sobre a alteridade. Rio de Janeiro: Mauad, 2006. v.1. p.181-206.

RIBEIRO, A. P. G. A história da imprensa no Brasil: um balanço teórico e metodológico. In: ENCONTRO DA REDE ALCAR. Palestra... Niterói: UFF, 2008.

RICOEUR, P. Tempo e narrativa. Campinas: Papirus, 1997. v.3.

SANTOS, A. Travessias comunicacionais de um tipografo jornalista: José Diamantino de Assis e as tessituras do moderno. 2016. 242 f. Tese (Doutorado em Comunicação) - Universidade Federal do Rio de Janeiro, Rio de Janeiro.

SILVA, M. A. R. Jornalistas pra quê? Militância sindical e o drama da identidade profissional. 2007. 258 f. Tese (Doutorado em Comunicação) - Universidade Federal Fluminense, Niterói.

SODRÉ, M. Antropológica do espelho. Petrópolis: Vozes, 2002.

A ciência do comum. Petrópolis: Vozes, 2014.

WEBER, M. A objetividade do conhecimento nas ciências sociais. In: COHN, G. (Org.). Weber: sociologia. São Paulo: Ática, 1999 (Coleção Grandes Cientistas Sociais, 13). p.79-127.

\section{Marialva Barbosa}

Pós-doutora em Comunicação (LAIOS/CNRS), doutora em História pela Universidade Federal Fluminense (UFF) e professora titular da Escola de Comunicação da Universidade Federal do Rio de Janeiro (ECO-UFRJ). Dedica-se há mais de duas décadas a estudar a história dos meios de comunicação, tendo publicado diversos artigos e livros sobre o tema, entre eles: História cultural da imprensa - 1800-1900 (2010) e História cultural da imprensa - 1900-2000 (2007), ambos pela Editora Mauad X; História da comunicação no Brasil (2013), pela Editora Vozes; e Escravos e mundo da comunicação (2016), também pela Editora Mauad X. Foi diretora científica, vice-presidente e presidente da Sociedade Brasileira de Estudos Interdisciplinares da Comunicação (Intercom) (2014-2017). Pesquisadora 1D do Conselho Nacional de Desenvolvimento Científico e Tecnológico (CNPq).E-mail: marialva153@gmail.com.

Recebido em: 21.09.2017

Aprovado em: 02.04.2018

Este artigo é publicado em acesso aberto (Open Access) sob a licença Creative Commons Attribution Non-Commercial (CC-BY-NC), que permite uso, distribuição e reprodução em qualquer meio, sem restrições, desde que sem fins comerciais e que o trabalho original seja corretamente citado. 